\title{
Review Article \\ The Inflammatory Actions of Coagulant and Fibrinolytic Proteases in Disease
}

\author{
Michael Schuliga \\ Lung Health Research Centre, Department of Pharmacology and Therapeutics, University of Melbourne, Parkville, VIC 3010, Australia \\ Correspondence should be addressed to Michael Schuliga; schuliga@unimelb.edu.au
}

Received 31 December 2014; Revised 2 March 2015; Accepted 16 March 2015

Academic Editor: Alex Kleinjan

Copyright (C) 2015 Michael Schuliga. This is an open access article distributed under the Creative Commons Attribution License, which permits unrestricted use, distribution, and reproduction in any medium, provided the original work is properly cited.

Aside from their role in hemostasis, coagulant and fibrinolytic proteases are important mediators of inflammation in diseases such as asthma, atherosclerosis, rheumatoid arthritis, and cancer. The blood circulating zymogens of these proteases enter damaged tissue as a consequence of vascular leak or rupture to become activated and contribute to extravascular coagulation or fibrinolysis. The coagulants, factor Xa (FXa), factor VIIa (FVIIa), tissue factor, and thrombin, also evoke cell-mediated actions on structural cells (e.g., fibroblasts and smooth muscle cells) or inflammatory cells (e.g., macrophages) via the proteolytic activation of proteaseactivated receptors (PARs). Plasmin, the principle enzymatic mediator of fibrinolysis, also forms toll-like receptor-4 (TLR-4) activating fibrin degradation products (FDPs) and can release latent-matrix bound growth factors such as transforming growth factor- $\beta$ (TGF- $\beta$ ). Furthermore, the proteases that convert plasminogen into plasmin (e.g., urokinase plasminogen activator) evoke plasmin-independent proinflammatory actions involving coreceptor activation. Selectively targeting the receptor-mediated actions of hemostatic proteases is a strategy that may be used to treat inflammatory disease without the bleeding complications of conventional anticoagulant therapies. The mechanisms by which proteases of the coagulant and fibrinolytic systems contribute to extravascular inflammation in disease will be considered in this review.

\section{Introduction}

As part of hemostasis, the coagulation and fibrinolytic pathways regulate vascular repair by forming and degrading fibrin, respectively [1]. In disease, increased vascular permeability allows blood-circulating hemostatic factors such as factor $\mathrm{X}(\mathrm{FX})$ and plasminogen to enter damaged tissue to become activated and participate in coagulation or fibrinolysis. Fibrin deposition within damaged tissues is a common pathological feature and evidence of extravascular coagulation in inflammatory diseases including many respiratory and vascular diseases [2-5], rheumatoid arthritis [6], and cancer [7]. Aside from roles in fibrin homeostasis, several of the coagulant and fibrinolytic proteases exert potent proinflammatory and proremodelling actions in disease. These actions may be independent of fibrin formation, such as the activation of protease-activated receptor-1 (PAR-1) on extravascular cells by the coagulants, thrombin [8] and FXa [9], and the fibrinolytic mediator, plasmin [10] (Figure 1). The proteases which convert plasminogen into plasmin, urokinase- and tissue-type plasminogen activators (uPA and tPA, resp.), also directly signal through receptors, such as uPAR [11] and LDL receptor-related protein 1 (LRP-1) [12], involving integrin recruitment, to mediate proremodelling activities (Figure 1). Other extravascular actions of coagulants and fibrinolytic proteases are less direct, such as those of plasmin, which involve the formation of fibrin degradation products (FDPs) [13] or activation of matrix metalloproteinases (MMPs) and subsequent release of matrix-bound growth factors (transactivation) [14] (Figure 1).

\section{Extravascular Coagulation in Disease}

Extravascular accumulation of fibrin, formed by the coagulation cascade, occurs in a number of diseases [2-7]. In tissue injury and inflammation, plasma containing FVII and FX leaks into the extravascular compartment [15-18]. FVII, combined with surface bound tissue factor (TF), which is formed by mesenchymal, epithelial, and inflammatory cells, transforms FX into the serine protease, FXa. The latter, combined with factor $\mathrm{V}(\mathrm{FV})$, activates thrombin, which in 


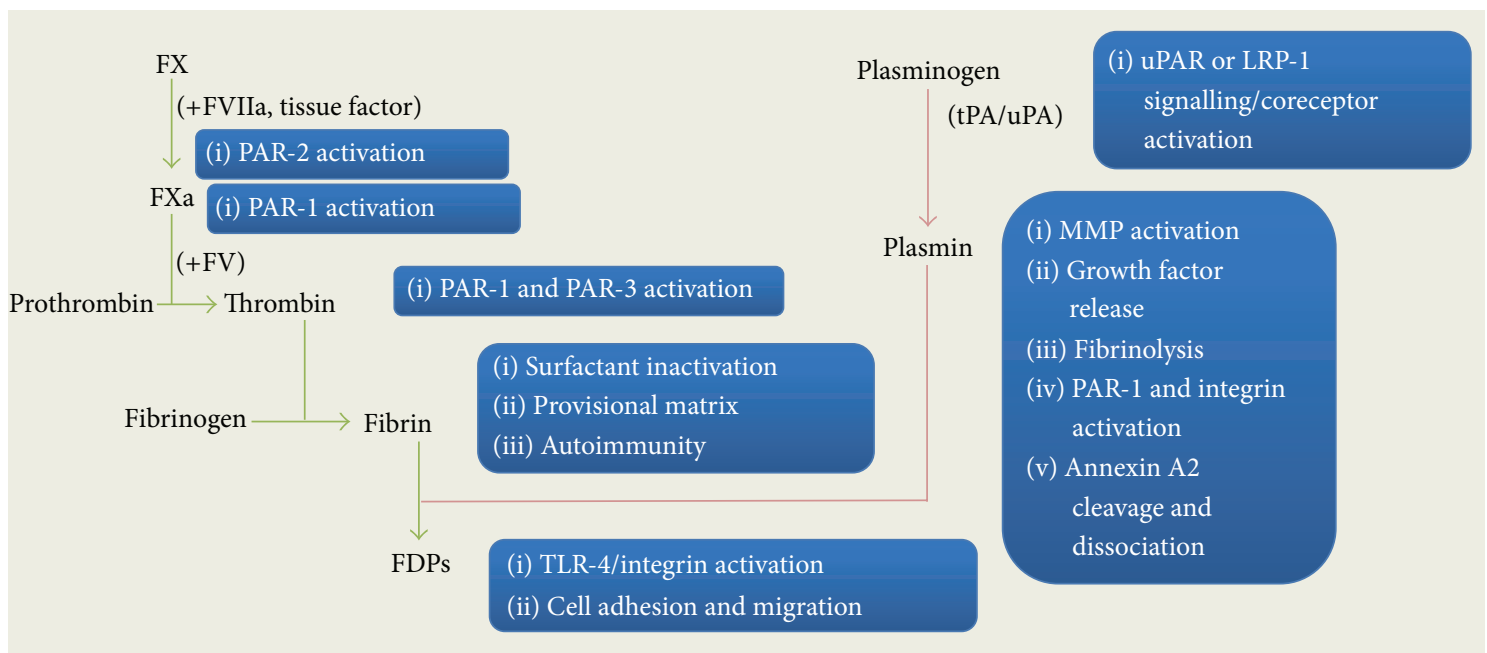

FIGURE 1: The proinflammatory and proremodelling actions of coagulant and fibrinolytic proteases. In tissue injury and disease, the proteases FXa, FVIIa, thrombin, plasmin, uPA, and tPA not only participate in extravascular coagulation (green pathway) or fibrinolysis (red pathway), but also mediate inflammation and tissue remodelling. The cell-mediated actions of the individual proteases can overlap (i.e., PAR-1 activation by FXa, thrombin, and plasmin) and/or be interconnected (i.e., the generation of FDPs by both coagulation and fibrinolytic pathways).

turn converts fibrinogen into fibrin. Abundant extravascular fibrin is a specific hallmark of lung injury and disease including acute lung injury (ALI) [2], asthma [3], and idiopathic pulmonary fibrosis (IPF) [4]. Increased levels of coagulant factors or activity are also detected in the induced sputum and bronchial lavage fluid of patients with respiratory disease $[19,20]$, particularly after exacerbation following rhinovirus infection [21]. Furthermore, endogenous FX is expressed in the lung tissue of IPF patients, localized to alveolar epithelial cells, macrophages, and myofibroblasts in fibrotic foci [22]. In rheumatoid arthritis, fibrin accumulates within inflamed hyperplastic synovial tissue and fluid of arthritic joints [6]. Deposits of insoluble fibrin on synovial membranes and pannus relate to the progression of arthritis [23]. In vascular disease, fibrin is present in normal arterial intima and in atherosclerotic lesions, particularly early proliferative, gelatinous-lesions [5]. In cancer, fibrin is detected surrounding carcinoma cells, particularly at the interface with surrounding stromal cells and blood vessels [7]. In disease, the deposition of fibrin into the extracellular matrix serves as a scaffold to support proliferation, migration, and growth of either mesenchymal (i.e., smooth muscle and fibroblasts) or tumor cells. In respiratory disease, excess accumulation of airspace fibrin is detrimental as it inactivates surfactant [24, 25]. In rheumatoid arthritis, fibrin becomes autoantigenic by the posttranslational modification, citrullination, possibly contributing to inflammation via a TLR-4 pathway [26].

\section{Extravascular Fibrinolysis in Disease}

Fibrinolysis is the counterpart of coagulation. The key mediator of fibrinolysis is plasmin, which is formed by the proteolytic activation of plasminogen by either tPA or uPA $[27,28]$. Plasmin function actually differs depending on where it is formed and by which activator [29]. Fibrinolysis per se is associated with tPA, which unlike uPA shows fibrin-enhanced proteolytic activity [25]. In interstitial tissue, uPA is the predominant means of plasminogen activation, contributing to pericellular proteolysis and cell activation [30]. Whilst plasmin has an important role in the resolution phase of wound-repair processes in damaged tissue by degrading fibrin [31] or by activating structural and inflammatory cells [14, 32-34], excessive formation of plasmin is potentially harmful. In vascular disease and injury, extravascular plasminogen activation is considered to contribute to tissue remodelling in the vascular wall by stimulating the proliferation and migration of vascular smooth muscle cells in neointima formation $[35,36]$. In rheumatoid arthritis, synovial levels of fibrin D-dimer, a measure of fibrinolysis, correlates with disease severity and response to therapy $[37,38]$. Acute tPA-mediated plasmin formation is a critical component of extravascular proteolytic damage in immature brains caused by hypoxiaischemia [39]. In lung injury and disease, whilst suppressed tPA-mediated fibrinolysis contributes to the accumulation of airspace fibrin [40], increased uPA activity in the interstitium of damaged lung tissue favors temporal and localized increases in plasmin production [41-43]. The proteolytic activity of plasmin, whether via the formation of TLR-4activating FDPs or by the activation of MMPs and/or PAR-1, contributes to inflammation and remodelling in disease.

\section{Regulation of Coagulation and Fibrinolysis}

Coagulation and fibrinolysis in physiological wound repair are highly regulated and integrated processes. The important negative regulator of coagulation, thrombomodulin, binds thrombin to prevent it from cleaving fibrinogen or activating PAR-1. Thrombomodulin-thrombin complexes also activate the anticoagulant, protein C. Hereditary deficiency of protein 


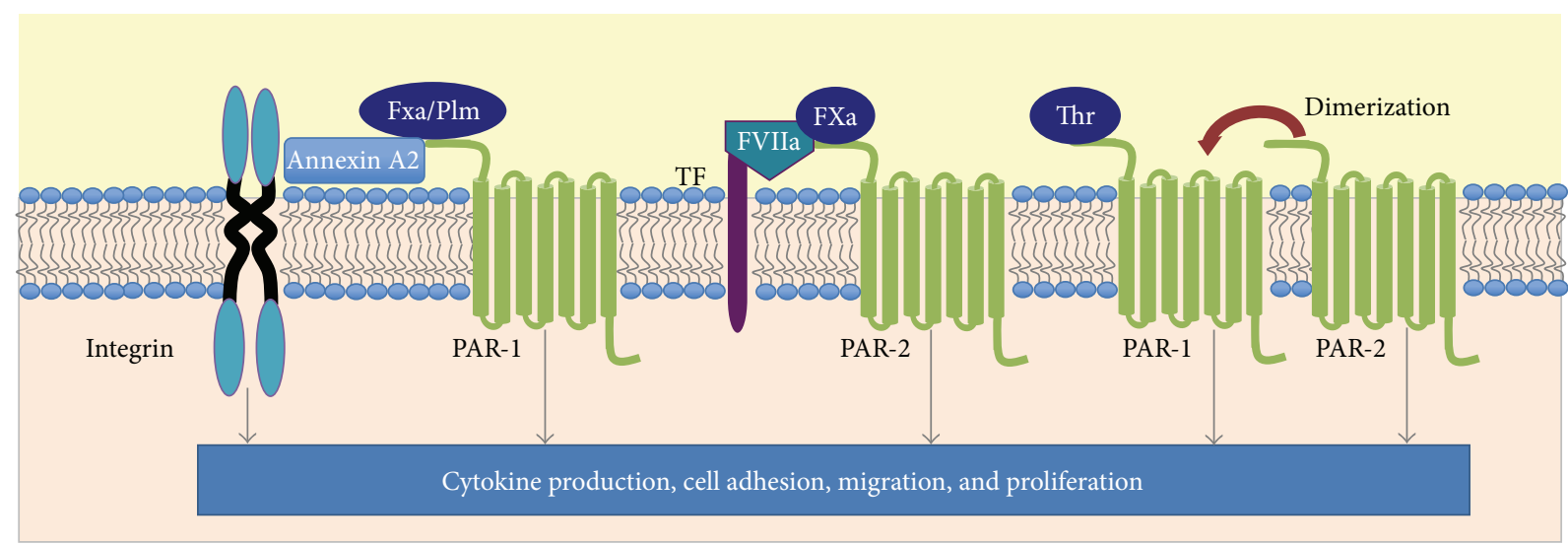

FIgURE 2: PAR signalling by coagulant and fibrinolytic proteases. Thrombin (thr), FXa, FVIIa, and plasmin (Plm) can signal via different combinations of PARs, coreceptors (e.g., $\alpha_{9} \beta_{1}$-integrin), and adaptors (e.g., annexin A2). Modulation of signalling may also involve PAR dimerization.

$\mathrm{C}$ is an established risk factor for venous thrombosis [44], as activated protein $\mathrm{C}$ (APC) cleaves and inactivates the coagulants, FVa and factor VIIIa (FVIIIa). Plasminogen and plasminogen activator coreceptors that accelerate and localize plasmin formation to the cell surface, such as uPAR and the annexin A2 heterotetramer (AIIt) [28], are important regulators of fibrinolysis. Fibrinolysis is negatively regulated by the serpin, plasminogen activator inhibitor 1 (PAI-1), which covalently binds to and inactivates plasminogen activators. PAI-1 levels are higher in many respiratory diseases [45-48]. Direct effects of PAI-1 on cells, independent of plasmin formation, may also contribute to disease pathology [49]. Another serpin, $\alpha 2$-antiplasmin, inactivates plasmin by binding its soluble but not fibrin-bound form [50]. Hyperfibrinolytic bleeding occurs in a number of diseases including chronic liver disease as a consequence of decreased production or loss of $\alpha 2$-antiplasmin [51].

There are a number of interaction points between coagulation and fibrinolysis. Thrombomodulin-bound thrombin activates thrombin activated fibrinolysis inhibitor (TAFI). This carboxypeptidase removes $\mathrm{C}$-terminal lysine and arginine residues on fibrin, reducing plasminogen binding, hence activation and subsequent break down of fibrin. Increased levels of activated TAFI are associated with a number of diseased states including cardiovascular [52] and inflammatory bowel [53] diseases. TAFI can also cleave and inactivate uPA whereas plasmin can cleave and inactivate a number of coagulants including FVa, FVIIIa, and FXa. Plasmin proteolysis of FXa reveals a cryptic binding site for TPA in the cleaved product (denoted as $\beta \mathrm{FXa}$ ) [54]. As binding of $\beta \mathrm{FXa}$ to tPA accelerates fibrinolysis [55], FXa-proteolysis is a pivotal switch from coagulation to fibrinolysis.

\section{PAR Activation}

The PARs (PAR-1, -2, -3, and -4) are a G protein-coupled receptor family, activated by proteolysis of the $\mathrm{N}$-terminus to reveal a tethered ligand. PAR-1 is the prototypical receptor of thrombin (and FXa) (Figure 2), although PAR-3 and -4 can be activated by thrombin also. PAR-2 is activated by complexes of either TF:FVIIa or TF:FVIIa:FXa [9, 56] (Figure 2). PARs are expressed in inflammatory cells including macrophages, mast cells, and eosinophils [57-60] and extravascular structural cells including epithelial, smooth muscle, and fibroblast cells [61]. Levels of PARs are increased in structural cells in fibrotic lung disease [62], and targeting PAR-1 reduces pulmonary inflammation and fibrosis in mouse models of lung injury and disease $[22,59,63]$. Furthermore, PAR-1 activation elicits increased cytokine and collagen expression [22, 64, 65] and proliferation [66] of lung mesenchymal cells. The upregulation of both PAR-1 and PAR-2 in vascular smooth muscle cells following injury and activation by hemostatic proteases is considered to contribute to the pathogenesis of atherosclerosis [67]. PAR-1, along with PAR-4, also appears to play an important role in cancer, mediating thrombin-evoked tumor cell migration [68]. In rheumatoid arthritis, PAR-1 and PAR-2 expression is increased in synovial fibroblasts, although it appears PAR-2 is the primary mediator of synovial fibroblast growth, invasion, and cytokine production [69].

\section{PAR Coreceptors and Dimerization}

PAR signalling is modulated by coreceptors and adaptors. An example is the dependency of the PAR-1-mediated cytoprotective effects of the anticoagulant, APC for the endothelial $\mathrm{PC}$ receptor (EPCR) or C11b integrin [70, 71]. Whilst plasmin has $\sim 10$ times less affinity for PAR-1 than thrombin [8], integrin coreceptors augment plasmin-evoked PAR-1 activation [10]. Binding to $\alpha_{9} \beta_{1}$ integrin localizes plasmin to the cell surface and protects it from $\alpha 2$-antiplasmin inhibition, increasing PAR-1 activation, whilst also activating pathways downstream of $\alpha_{9} \beta_{1}$ integrin through integrin-linked kinase (ILK) [10] (Figure 2). Annexin A2, a mediator of plasminstimulated cytokine production in macrophages and smooth muscle cells [14, 33, 72], also binds and protects plasmin from $\alpha 2$-antiplasmin inhibition [73]. Annexin A2 may facilitate plasmin localization to the cell surface and subsequent PAR-1 
and integrin coactivation [74]. Annexin A2 also binds FXa to augment FXa-mediated activation of PAR-1 [9] (Figure 2).

\section{PAR Dimerization}

PAR-PAR interactions, such as PAR-2 transactivation by PAR-1, also modulate cellular responses evoked by coagulant and fibrinolytic proteases [75]. PAR-1 activation in tumor cells stimulates either rapid uPA release or increased plasminogen activator inhibitor-1 (PAI-1) expression, depending on whether PAR-1 is dimerized to PAR-2 [76]. Cooperative PAR1 and PAR-4 signalling contributes to thrombin-mediated cancer cell migration [68]. Figure 2 summarizes the different configurations of PARs and coreceptors in mediating the actions of coagulants and plasmin.

\section{Growth Factor Receptor Transactivation}

Plasmin catalyzes the proteolytic activation of MMPs, which not only can activate PAR-1, but release the otherwise latent forms of growth factors such as epidermal growth factor (EGF) and TGF- $\beta[77,78]$. Plasmin is involved in the activation of a number of MMPs including MMP-1, MMP-2, MMP3, MMP-9, MMP-13, and MMP-14 [79]. Plasminogen activation by smooth muscle cells and fibroblasts is associated with MMP activation [80] and targeting the EGF-receptor (EGFR) or MMPs attenuates plasmin(ogen)-stimulated proliferation [14]. The effects of plasmin(ogen) on EGFR signalling are contributed by heparin-binding EGF, an EGFR ligand, which is released from cell surface heparan sulphate proteoglycan by MMP-mediated proteolysis. In a manner similar to EGFR transactivation, plasmin-stimulated mobilization of matrixbound TGF- $\beta$ contributes to collagen synthesis in smooth muscle cells in a manner involving TGF- $\beta$ receptor signalling [77]. Additionally, the plasmin-activated MMP-1 and MMP13 also cleave the N-terminal exodomain of PAR-1, but at sites alternative to those of thrombin and FXa, to elicit distinct cellular responses thought to be relevant in cancer and rheumatoid arthritis pathology [81].

\section{Plasmin-Independent Actions of uPA}

Increased levels of uPA occur in many pathologies, including chronic respiratory and vascular disease $[45,46,48,82,83]$, rheumatoid arthritis [84], and cancer [85]. Aside from its role in plasmin formation, uPA also elicits cellular responses via binding its receptor, uPAR, which lacks a transmembrane or intracellular domain. The aminoterminal fragment of uPA interacts with uPAR to activate coreceptors including the formyl-peptide receptor 2 (FPR2) [86], EGFR [87], and integrins [11] to regulate migration, chemotaxis, and cytokine production. Integrin binding extracellular matrix (ECM) proteins such as fibulin 5 and vitronectin modulate uPAuPAR signalling [88]. In an uPAR-independent manner, the kringle domain of uPA interacts with the $\alpha_{v} \beta_{1}$-integrin to elicit intracellular signalling and cell migration [89].

\section{Fibrin(ogen) Fragments in Inflammation}

The coagulation and plasminogen activation systems also contribute to inflammation by their respective roles in the formation and subsequent break down of fibrin. Fibrinogen cleavage by thrombin releases the fibrinopeptides A and B, which are potent chemoattractants for neutrophils, monocytes, and macrophages [90, 91]. Fibrin and FDPs activate inflammatory and/or structural cells via binding TLR-4 [13] or CD11b/CD18 integrins [92] and regulate smooth muscle cell migration via binding $\alpha_{5} \beta_{3}$ integrin [93]. Fibrin Ddimers, a biomarker for hyperfibrinolytic disorders such as disseminated intravascular coagulation (DIC), stimulate increased cytokine production in peripheral blood monocytes and leukemia cell lines [94, 95]. Fibrin fragment E induces leukocyte cytokine expression and migration by binding vascular endothelial-cadherin and monocyte and neutrophil migration by binding CD11c [96]. The small FDP, $\mathrm{B} \beta 15-42$, is a potent chemoattractant for neutrophils and fibroblasts and induces cytokine expression in human oral squamous cell carcinoma cells [97]. However, B $\beta 15-42$ also has anti-inflammatory and immunosuppressive actions which are considered to be protective in ischemia reperfusion injury and hemorrhagic shock $[98,99]$. FXa may also be an endogenous activator of the innate immune system as FXa is required for adenoviral activation of TLR-4/MyD88 signalling in host cells [100]. TLR-4 activation by FXa may involve its binding partner, annexin A2 [9]. Annexin A2 activates TLR- 4 to regulate smooth muscle cell proliferation and macrophage cytokine production $[14,101]$ and is an "adaptor" for TLR-4 in a multiprotein signalling scaffold on endothelial cells in antiphospholipid syndrome [102]. Interestingly, plasmin also has a role in the innate immune system by inducing the dissociation of annexin $\mathrm{A} 2$ from the extracellular heterotetrameric complex it forms with S100A10, allowing monomeric annexin A2 to activate TLR-4 [103].

\section{Inflammatory Actions of Coagulant Proteases Are Glucocorticoid-Insensitive}

Synthetic glucocorticoids (GCs) are the most effective antiinflammatory therapy for disease including rheumatic diseases, allergy, asthma, and sepsis. However, GC resistance limits the therapeutic response of GCs in certain chronic inflammatory diseases including severe asthma, IPF, and cancer [104]. GC resistance has been attributed to cellular microenvironment changes, that is, alterations in the ECM, as a consequence of chronic inflammation [105]. Thrombin is a GC-insensitive mediator of inflammation and remodelling based on its response requiring 100-fold greater concentrations of dexamethasone than those of IL-1 $\alpha$ and other cytokines [106]. Integrins may render the PAR-mediated actions of coagulant proteases insensitive to GCs. $\beta_{1}$-integrin mediates diminished GC responsiveness in smooth muscle cells [107], and the $\beta_{6}$-integrin is responsible for impaired skin wound healing caused by GCs [108]. Interestingly, the integrin binding annexin A2 has a role in GC resistance in leukemia [109]. 


\section{Selectively Targeting Coagulation Proteases as Therapy}

Targeting coagulation protease activity or signalling is a potential treatment for inflammatory disease. However, anticoagulant therapies, including selective small molecule FXa inhibitors used to treat thrombotic diseases (e.g., Apixaban), are typically associated with potentially fatal bleeding risks [110]. Furthermore, orally administered PAR-1 inhibitors such as Vorapaxar, whilst not affecting fibrin formation, suppress thrombin-stimulated platelet aggregation, hence interfering with hemostasis. Vorapaxar is used for prevention of secondary thrombotic cardiovascular events in patients with a prior myocardial infarction [111], despite having been withdrawn from phase III trials as treatment for acute coronary syndrome due to bleeding complications [112]. Improved inhibitors, that selectively target the extravascular cell-mediated actions of coagulant proteases without disrupting hemostasis, are likely to have greater therapeutic windows as treatment for inflammation. The design of such inhibitors may take advantage of coreceptors and adaptors that differentiate PAR responses in platelet and endothelial cells as compared to inflammatory and extravascular structural cells.

\section{Therapeutic Potential of Targeting Fibrinolytic Proteases}

Selective targeting interstitial plasmin formation is another potential strategy to treat chronic inflammatory disease. Highly selective small molecule inhibitors of uPA such as $W X-U K 1$ have been evaluated in preclinical and clinical studies to assess whether uPA is a potential target to treat cancer [113-115]. In clinical trial programs, oral administration of uPA inhibitors was assessed to be well-tolerated and provided promising results, which greatly increase their translational potential as anti-inflammatory therapies. Functional blocking antibodies for uPA and/or uPAR have also been evaluated in preclinical studies of cancer, hepatic fibrinolysis, and ALI [116-118], providing evidence for the feasibility of targeting uPA using antibody-based strategies. Annexin A2, a regulator of plasmin formation and signalling, is implicated in cancer with its levels elevated in various tumors [119, 120]. The systemic administration of annexin A2 antibody inhibits tumour growth and metastasis in murine cancer models in vivo without detectable toxicity $[121,122]$.

\section{Conclusion}

Coagulant and fibrinolytic proteases evoke proinflammatory and remodelling actions in disease. Coagulants, plasminogen activators, plasmin, and plasmin-activated MMPs evoke cellmediated responses via receptors (e.g., PARs and uPAR) and coreceptors (e.g., integrins and FPR2). Plasmin also indirectly contributes to inflammatory processes by forming FDPs or by growth factor receptor transactivation. Targeting the inflammatory actions of coagulant and/or fibrinolytic proteases without disrupting hemostasis is a strategy that may be beneficial in the treatment of inflammatory disease.

\author{
Abbreviations \\ ALI: Acute lung injury \\ EGF: Epidermal growth factor \\ ECM: Extracellular matrix \\ FV: $\quad$ Factor $\mathrm{V}$ \\ FVII: Factor VII \\ FX: Factor X \\ FXa: Factor $\mathrm{X}$ activated \\ FDPs: Fibrin degradation products \\ FPR2: Formyl-peptide receptor 2 \\ GCs: Glucocorticoids \\ IPF: Idiopathic pulmonary fibrosis \\ LRP-1: LDL receptor-related protein 1 \\ MMP: Matrix metalloproteinases \\ PAR: Protease-activated receptor \\ TF: $\quad$ Tissue factor \\ tPA: Tissue type-plasminogen activator \\ TLR-4: Toll-like receptor-4 \\ TGF- $\beta$ : Transforming growth factor- $\beta$ \\ uPA: Urokinase plasminogen activator \\ uPAR: uPA receptor.
}

\section{Conflict of Interests}

The author declares that there is no conflict of interests regarding the publication of this paper.

\section{References}

[1] H. H. Versteeg, J. W. M. Heemskerk, M. Levi, and P. H. Reitsma, "New fundamentals in hemostasis," Physiological Reviews, vol. 93, no. 1, pp. 327-358, 2013.

[2] T. Tucker and S. Idell, "Plasminogen-plasmin system in the pathogenesis and treatment of lung and pleural injury," Seminars in Thrombosis and Hemostasis, vol. 39, no. 4, pp. 373-381, 2013.

[3] S. S. Wagers, R. J. Norton, L. M. Rinaldi, J. H. T. Bates, B. E. Sobel, and C. G. Irvin, "Extravascular fibrin, plasminogen activator, plasminogen activator inhibitors, and airway hyperresponsiveness," Journal of Clinical Investigation, vol. 114, no. 1, pp. 104-111, 2004.

[4] P. W. Noble, C. E. Barkauskas, and D. Jiang, "Pulmonary fibrosis: patterns and perpetrators," The Journal of Clinical Investigation, vol. 122, no. 8, pp. 2756-2762, 2012.

[5] E. B. Smith, "Fibrinogen, fibrin and the arterial wall," European Heart Journal, vol. 16, supplement A, pp. 11-15, 1995.

[6] H. Raghu and M. J. Flick, "Targeting the coagulation factor fibrinogen for arthritis therapy," Current Pharmaceutical Biotechnology, vol. 12, no. 9, pp. 1497-1506, 2011.

[7] F. W. Schardt, B. Schmausser, and E. Bachmann, "Monoclonal antibodies for immunodetection of fibrin deposits on cancer cells," Histology and Histopathology, vol. 28, no. 8, pp. 993-998, 2013.

[8] L. M. Altrogge and D. Monard, "An assay for high-sensitivity detection of thrombin activity and determination of proteases activating or inactivating protease-activated receptors," Analytical Biochemistry, vol. 277, no. 1, pp. 33-45, 2000. 
[9] G. Bhattacharjee, J. Ahamed, R. Pawlinski et al., "Factor Xa binding to annexin 2 mediates signal transduction via proteaseactivated receptor 1," Circulation Research, vol. 102, no. 4, pp. 457-464, 2008.

[10] M. Majumdar, T. Tarui, B. Shi, N. Akakura, W. Ruf, and Y. Takada, "Plasmin-induced migration requires signaling through protease-activated receptor 1 and integrin $\alpha_{9} \beta_{1}$," Journal of Biological Chemistry, vol. 279, no. 36, pp. 37528-37534, 2004.

[11] Y. Wei, J. A. Eble, Z. Wang, J. A. Kreidberg, and H. A. Chapman, "Urokinase receptors promote betal integrin function through interactions with integrin alpha3betal," Molecular Biology of the Cell, vol. 12, no. 10, pp. 2975-2986, 2001.

[12] K. Hu, C. Wu, W. M. Mars, and Y. Liu, "Tissue-type plasminogen activator promotes murine myofibroblast activation through LDL receptor-related protein 1-mediated integrin signaling," The Journal of Clinical Investigation, vol. 117, no. 12, pp. 3821-3832, 2007.

[13] V. O. Millien, W. Lu, J. Shaw et al., "Cleavage of fibrinogen by proteinases elicits allergic responses through toll-like receptor 4," Science, vol. 341, no. 6147, pp. 792-796, 2013.

[14] A. G. Stewart, Y. C. Xia, T. Harris, S. Royce, J. A. Hamilton, and M. Schuliga, "Plasminogen-stimulated airway smooth muscle cell proliferation is mediated by urokinase and annexin A2, involving plasmin-activated cell signalling," British Journal of Pharmacology, vol. 170, no. 7, pp. 1421-1435, 2013.

[15] B. N. Lambrecht and H. Hammad, "Asthma and coagulation," The New England Journal of Medicine, vol. 369, no. 20, pp. 19641966, 2013.

[16] J. D. de Boer, C. J. Majoor, C. Van't Veer, E. H. D. Bel, and T. van der Poll, "Asthma and coagulation," Blood, vol. 119, no. 14, pp. 3236-3244, 2012.

[17] R. A. Campbell, K. A. Overmyer, C. H. Selzman, B. C. Sheridan, and A. S. Wolberg, "Contributions of extravascular and intravascular cells to fibrin network formation, structure, and stability," Blood, vol. 114, no. 23, pp. 4886-4896, 2009.

[18] H. F. Dvorak, D. R. Senger, A. M. Dvorak, V. S. Harvey, and J. McDonagh, "Regulation of extravascular coagulation by microvascular permeability," Science, vol. 227, no. 4690, pp. 1059-1061, 1985.

[19] F. J. H. Brims, A. J. Chauhan, B. Higgins, and J. K. Shute, "Coagulation factors in the airways in moderate and severe asthma and the effect of inhaled steroids," Thorax, vol. 64, no. 12, pp. 1037-1043, 2009.

[20] A. Günther, P. Mosavi, C. Ruppert et al., "Enhanced tissue factor pathway activity and fibrin turnover in the alveolar compartment of patients with interstitial lung disease," Thrombosis and Haemostasis, vol. 83, no. 6, pp. 853-860, 2000.

[21] C. J. Majoor, M. A. van de Pol, P. W. Kamphuisen et al., "Evaluation of coagulation activation after rhinovirus infection in patients with asthma and healthy control subjects: an observational study," Respiratory Research, vol. 15, article 14, 2014.

[22] C. J. Scotton, M. A. Krupiczojc, M. Königshoff et al., "Increased local expression of coagulation factor $\mathrm{X}$ contributes to the fibrotic response in human and murine lung injury," The Journal of Clinical Investigation, vol. 119, no. 9, pp. 2550-2563, 2009.

[23] F. Carmassi, F. de Negri, M. Morale, K. Y. Song, and S. I. Chung, "Fibrin degradation in the synovial fluid of rheumatoid arthritis patients: a model for extravascular fibrinolysis," Seminars in Thrombosis and Hemostasis, vol. 22, no. 6, pp. 489-496, 1996.
[24] N. N. Jarjour and G. Enhorning, "Antigen-induced airway inflammation in atopic subjects generates dysfunction of pulmonary surfactant," The American Journal of Respiratory and Critical Care Medicine, vol. 160, no. 1, pp. 336-341, 1999.

[25] S. Wagers, L. K. A. Lundblad, M. Ekman, C. G. Irvin, and J. H. T. Bates, "The allergic mouse model of asthma: normal smooth muscle in an abnormal lung?" Journal of Applied Physiology, vol. 96, no. 6, pp. 2019-2027, 2004.

[26] O. Sanchez-Pernaute, M. Filkova, A. Gabucio et al., "Citrullination enhances the pro-inflammatory response to fibrin in rheumatoid arthritis synovial fibroblasts," Annals of the Rheumatic Diseases, vol. 72, no. 8, pp. 1400-1406, 2013.

[27] J. Kim and K. A. Hajjar, "Annexin II: a plasminogenplasminogen activator co-receptor," Frontiers in Bioscience, vol. 7, pp. d341-d348, 2002.

[28] P. A. Madureira, A. P. Surette, K. D. Phipps, M. A. S. Taboski, V. A. Miller, and D. M. Waisman, "The role of the annexin A2 heterotetramer in vascular fibrinolysis," Blood, vol. 118, no. 18, pp. 4789-4797, 2011.

[29] H. C. Kwaan and B. McMahon, "The role of plasminogenplasmin system in cancer," Cancer Treatment and Research, vol. 148, pp. 43-66, 2009.

[30] M. Del Rosso, F. Margheri, S. Serratì, A. Chillà, A. Laurenzana, and G. Fibbi, "The urokinase receptor system, a key regulator at the intersection between inflammation, immunity, and coagulation," Current Pharmaceutical Design, vol. 17, no. 19, pp. 19241943, 2011.

[31] C. M. Swaisgood, E. L. French, C. Noga, R. H. Simon, and V. A. Ploplis, "The development of bleomycin-induced pulmonary fibrosis in mice deficient for components of the fibrinolytic system," The American Journal of Pathology, vol. 157, no. 1, pp. 177-187, 2000.

[32] C. E. Stewart, H. S. Nijmeh, C. E. Brightling, and I. Sayers, "UPAR regulates bronchial epithelial repair in vitro and is elevated in asthmatic epithelium," Thorax, vol. 67, no. 6, pp. 477487, 2012.

[33] M. Schuliga, S. Langenbach, Y. C. Xia et al., "Plasminogenstimulated inflammatory cytokine production by airway smooth muscle cells is regulated by annexin A2," The American Journal of Respiratory Cell and Molecular Biology, vol. 49, no. 5, pp. 751-758, 2013.

[34] Q. Li, Y. Laumonnier, T. Syrovets, and T. Simmet, "Plasmin triggers cytokine induction in human monocyte-derived macrophages," Arteriosclerosis, Thrombosis, and Vascular Biology, vol. 27, no. 6, pp. 1383-1389, 2007.

[35] W. P. Fay, N. Garg, and M. Sunkar, "Vascular functions of the plasminogen activation system," Arteriosclerosis, Thrombosis, and Vascular Biology, vol. 27, no. 6, pp. 1231-1237, 2007.

[36] E. G. Levin and D. J. Loskutoff, "Comparative studies of the fibrinolytic activity of cultured vascular cells," Thrombosis Research, vol. 15, no. 5-6, pp. 869-878, 1979.

[37] B. J. Bloom, A. J. Alario, and L. C. Miller, "Persistent elevation of fibrin D-dimer predicts longterm outcome in systemic juvenile idiopathic arthritis," Journal of Rheumatology, vol. 36, no. 2, pp. 422-426, 2009.

[38] J. B. Weinberg, A. M. M. Pippen, and C. S. Greenberg, "Extravascular fibrin formation and dissolution in synovial tissue of patients with osteoarthritis and rheumatoid arthritis," Arthritis and Rheumatism, vol. 34, no. 8, pp. 996-1005, 1991.

[39] D. Yang and C. Y. Kuan, "Anti-tissue Plasminogen Activator (tPA) as an effective therapy of neonatal hypoxia-ischemia with 
and without inflammation," CNS Neuroscience \& Therapeutics, 2014.

[40] R. C. Chambers and C. J. Scotton, "Coagulation cascade proteinases in lung injury and fibrosis," Proceedings of the American Thoracic Society, vol. 9, no. 3, pp. 96-101, 2012.

[41] S. Shetty, A. Kumar, A. R. Johnson et al., "Differential expression of the urokinase receptor in fibroblasts from normal and fibrotic human lungs," The American Journal of Respiratory Cell and Molecular Biology, vol. 15, no. 1, pp. 78-87, 1996.

[42] M. A. Olman, N. Mackman, C. L. Gladson, K. M. Moser, and D. J. Loskutoff, "Changes in procoagulant and fibrinolytic gene expression during bleomycin-induced lung injury in the mouse," The Journal of Clinical Investigation, vol. 96, no. 3, pp. 1621-1630, 1995.

[43] T. Nishiuma, T. H. Sisson, N. Subbotina, and R. H. Simon, "Localization of plasminogen activator activity within normal and injured lungs by in situ zymography," The American Journal of Respiratory Cell and Molecular Biology, vol. 31, no. 5, pp. 552$558,2004$.

[44] L. Tjeldhorn, P. M. Sandset, K. Haugbro, and G. Skretting, "Hereditary protein C deficiency caused by the Ala267Thr mutation in the protein $\mathrm{C}$ gene is associated with symptomatic and asymptomatic venous thrombosis," Thrombosis Research, vol. 125, no. 3, pp. 230-234, 2010.

[45] F. J. H. Brims, A. J. Chauhan, B. Higgins, and J. K. Shute, "Up-regulation of the extrinsic coagulation pathway in acute asthma-a case Study," Journal of Asthma, vol. 47, no. 6, pp. 695698, 2010.

[46] K. Kowal, S. Zukowski, M. Moniuszko, and A. BodzentaŁukaszyk, "Plasminogen activator inhibitor-1 (PAI-1) and urokinase plasminogen activator (uPA) in sputum of allergic asthma patients," Folia Histochemica et Cytobiologica, vol. 46, no. 2, pp. 193-198, 2008.

[47] Z. Ma, D. Paek, and C. K. Oh, "Plasminogen activator inhibitor1 and asthma: role in the pathogenesis and molecular regulation," Clinical and Experimental Allergy, vol. 39, no. 8, pp. 11361144, 2009.

[48] W. Xiao, Y.-P. Hsu, A. Ishizaka, T. Kirikae, and R. B. Moss, "Sputum cathelicidin, urokinase plasminogen activation system components, and cytokines discriminate cystic fibrosis, COPD, and asthma inflammation," Chest, vol. 128, no. 4, pp. 2316-2326, 2005.

[49] T. Iwaki, T. Urano, and K. Umemura, "PAI-1, progress in understanding the clinical problem and its aetiology," British Journal of Haematology, vol. 157, no. 3, pp. 291-298, 2012.

[50] M. Schneider and M. Nesheim, "A study of the protection of plasmin from antiplasmin inhibition within an intact fibrin clot during the course of clot lysis," The Journal of Biological Chemistry, vol. 279, no. 14, pp. 13333-13339, 2004.

[51] A. Tripodi and P. M. Mannucci, "The coagulopathy of chronic liver disease," The New England Journal of Medicine, vol. 365, no. 2, pp. 147-156, 2011.

[52] D. A. Tregouet, R. Schnabel, M. C. Alessi et al., "Activated thrombin activatable fibrinolysis inhibitor levels are associated with the risk of cardiovascular death in patients with coronary artery disease: the AtheroGene study," Journal of Thrombosis and Haemostasis, vol. 7, no. 1, pp. 49-57, 2009.

[53] S. Saibeni, B. Bottasso, L. Spina et al., "Assessment of thrombinactivatable fibrinolysis inhibitor (TAFI) plasma levels in inflammatory bowel diseases," The American Journal of Gastroenterology, vol. 99, no. 10, pp. 1966-1970, 2004.
[54] E. L. G. Pryzdial and G. E. Kessler, "Autoproteolysis or plasminmediated cleavage of factor Xa $\alpha$ exposes a plasminogen binding site and inhibits coagulation," The Journal of Biological Chemistry, vol. 271, no. 28, pp. 16614-16620, 1996.

[55] K. Talbot, S. C. Meixner, and E. L. G. Pryzdial, "Enhanced fibrinolysis by proteolysed coagulation factor Xa," Biochimica et Biophysica Acta-Proteins and Proteomics, vol. 1804, no. 4, pp. 723-730, 2010.

[56] M. Åberg, M. Johnell, M. Wickström, and A. Siegbahn, “Tissue Factor/ FVIIa prevents the extrinsic pathway of apoptosis by regulation of the tumor suppressor Death-Associated Protein Kinase 1 (DAPK1)," Thrombosis Research, vol. 127, no. 2, pp. 141148, 2011.

[57] S. J. Bolton, C. A. McNulty, R. J. Thomas, C. R. A. Hewitt, and A. J. Wardlaw, "Expression of and functional responses to protease-activated receptors on human eosinophils," Journal of Leukocyte Biology, vol. 74, no. 1, pp. 60-68, 2003.

[58] G. R. Stenton, O. Nohara, R. E. Déry et al., "Proteinase-activated receptor (PAR)-1 and -2 agonists induce mediator release from mast cells by pathways distinct from PAR-1 and PAR-2," Journal of Pharmacology and Experimental Therapeutics, vol. 302, no. 2, pp. 466-474, 2002.

[59] W. Zhu, M. Bi, Y. Liu et al., "Thrombin promotes airway remodeling via protease-activated receptor-1 and transforming growth factor- $\beta 1$ in ovalbumin-allergic rats," Inhalation Toxicology, vol. 25 , no. 10, pp. 577-586, 2013.

[60] R. Colognato, J. R. Slupsky, M. Jendrach, L. Burysek, T. Syrovets, and T. Simmet, "Differential expression and regulation of protease-activated receptors in human peripheral monocytes and monocyte-derived antigen-presenting cells," Blood, vol. 102, no. 7, pp. 2645-2652, 2003.

[61] D. A. Knight, S. Lim, A. K. Scaffidi et al., "Protease-activated receptors in human airways: upregulation of PAR-2 in respiratory epithelium from patients with asthma," Journal of Allergy and Clinical Immunology, vol. 108, no. 5, pp. 797-803, 2001.

[62] P. F. Mercer, R. H. Johns, C. J. Scotton et al., "Pulmonary epithelium is a prominent source of proteinase-activated receptor-1inducible CCL2 in pulmonary Fibrosis," American Journal of Respiratory and Critical Care Medicine, vol. 179, no. 5, pp. 414425, 2009.

[63] D. C. J. Howell, R. H. Johns, J. A. Lasky et al., "Absence of proteinase-activated receptor-1 signaling affords protection from bleomycin-induced lung inflammation and fibrosis," The American Journal of Pathology, vol. 166, no. 5, pp. 1353-1365, 2005.

[64] A. Ortiz-Stern, X. Deng, N. Smoktunowicz, P. F. Mercer, and R. C. Chambers, "PAR-1-dependent and PAR-independent proinflammatory signaling in human lung fibroblasts exposed to thrombin," Journal of Cellular Physiology, vol. 227, no. 11, pp. 3575-3584, 2012.

[65] O. P. Blanc-Brude, F. Archer, P. Leoni et al., "Factor Xa stimulates fibroblast procollagen production, proliferation, and calcium signaling via PAR1 activation," Experimental Cell Research, vol. 304, no. 1, pp. 16-27, 2005.

[66] U. R. Pendurthi, M. Ngyuen, P. Andrade-Gordon, L. C. Petersen, and L. V. M. Rao, "Plasmin induces Cyr61 gene expression in fibroblasts via protease-activated receptor-1 and p44/42 mitogen-activated protein kinase-dependent signaling pathway," Arteriosclerosis, Thrombosis, and Vascular Biology, vol. 22, no. 9, pp. 1421-1426, 2002. 
[67] L. Martorell, J. Martínez-González, C. Rodríguez, M. Gentile, O. Calvayrac, and L. Badimon, "Thrombin and proteaseactivated receptors (PARs) in atherothrombosis," Thrombosis and Haemostasis, vol. 99, no. 2, pp. 305-315, 2008.

[68] R. Kaufmann, S. Rahn, K. Pollrich et al., “Thrombin-mediated hepatocellular carcinoma cell migration: cooperative action via proteinase-activated receptors 1 and 4," Journal of Cellular Physiology, vol. 211, no. 3, pp. 699-707, 2007.

[69] M. Xue, Y.-K. A. Chan, K. Shen et al., "Protease-activated receptor 2 , rather than protease-activated receptor 1 , contributes to the aggressive properties of synovial fibroblasts in rheumatoid arthritis," Arthritis and Rheumatism, vol. 64, no. 1, pp. 88-98, 2012.

[70] E. Kerschen, I. Hernandez, M. Zogg et al., "Activated protein C targets $\mathrm{CD}^{+}$dendritic cells to reduce the mortality of endotoxemia in mice," The Journal of Clinical Investigation, vol. 120, no. 9, pp. 3167-3178, 2010.

[71] C. Cao, Y. Gao, Y. Li, T. M. Antalis, F. J. Castellino, and L. Zhang, "The efficacy of activated protein $\mathrm{C}$ in murine endotoxemia is dependent on integrin CD11b," The Journal of Clinical Investigation, vol. 120, no. 6, pp. 1971-1980, 2010.

[72] Y. Laumonnier, T. Syrovets, L. Burysek, and T. Simmet, "Identification of the annexin A2 heterotetramer as a receptor for the plasmin-induced signaling in human peripheral monocytes," Blood, vol. 107, no. 8, pp. 3342-3349, 2006.

[73] T. J. MacLeod, M. Kwon, N. R. Filipenko, and D. M. Waisman, "Phospholipid-associated annexin A2-S100A10 heterotetramer and its subunits. Characterization of the interaction with tissue plasminogen activator, plasminogen, and plasmin," The Journal of Biological Chemistry, vol. 278, no. 28, pp. 25577-25584, 2003.

[74] L. Lin, C. Wu, and K. Hu, "Tissue plasminogen activator activates NF-kappaB through a pathway involving annexin A2/CD11b and integrin-linked kinase," Journal of the American Society of Nephrology, vol. 23, no. 8, pp. 1329-1338, 2012.

[75] H. Lin, A. P. Liu, T. H. Smith, and J. Trejo, "Cofactoring and dimerization of proteinase-activated receptors," Pharmacological Reviews, vol. 65, no. 4, pp. 1198-1213, 2013.

[76] T. A. McEachron, R. Pawlinski, K. L. Richards, F. C. Church, and N. Mackman, "Protease-activated receptors mediate crosstalk between coagulation and fibrinolysis," Blood, vol. 116, no. 23, pp. 5037-5044, 2010.

[77] A. Coutts, G. Chen, N. Stephens et al., "Release of biologically active TGF-beta from airway smooth muscle cells induces autocrine synthesis of collagen," The American Journal of Physiology-Lung Cellular and Molecular Physiology, vol. 280, no. 5, pp. L999-L1008, 2001.

[78] E. Roztocil, S. M. Nicholl, I. I. Galaria, and M. G. Davies, "Plasmin-induced smooth muscle cell proliferation requires epidermal growth factor activation through an extracellular pathway," Surgery, vol. 138, no. 2, pp. 180-186, 2005.

[79] E. I. Deryugina and J. P. Quigley, "Cell surface remodeling by plasmin: a new function for an old enzyme," Journal of Biomedicine and Biotechnology, vol. 2012, Article ID 564259, 21 pages, 2012.

[80] M. Schuliga, T. Harris, and A. G. Stewart, "Plasminogen activation by airway smooth muscle is regulated by type I collagen," The American Journal of Respiratory Cell and Molecular Biology, vol. 44, no. 6, pp. 831-839, 2011.

[81] K. M. Austin, L. Covic, and A. Kuliopulos, "Matrix metalloproteases and PAR1 activation," Blood, vol. 121, no. 3, pp. 431-439, 2013.
[82] S. Shetty, Y. P. Bhandary, S. K. Shetty et al., "Induction of tissue factor by urokinase in lung epithelial cells and in the lungs," American Journal of Respiratory and Critical Care Medicine, vol. 181, no. 12, pp. 1355-1366, 2010.

[83] Y. Zhang, W. Xiao, Y. Jiang et al., "Levels of components of the urokinase-type plasminogen activator system are related to chronic obstructive pulmonary disease parenchymal destruction and airway remodelling," Journal of International Medical Research, vol. 40, no. 3, pp. 976-985, 2012.

[84] A. D. Cook, C. M. De Nardo, E. L. Braine et al., "Urokinasetype plasminogen activator and arthritis progression: role in systemic disease with immune complex involvement," Arthritis Research and Therapy, vol. 12, no. 2, article R37, 2010.

[85] L. Tang and X. Han, "The urokinase plasminogen activator system in breast cancer invasion and metastasis," Biomedicine and Pharmacotherapy, vol. 67, no. 2, pp. 179-182, 2013.

[86] A. de Paulis, N. Montuori, N. Prevete et al., "Urokinase induces basophil chemotaxis through a urokinase receptor epitope that is an endogenous ligand for formyl peptide receptor-like 1 and like 2," The Journal of Immunology, vol. 173, no. 9, pp. 5739-5748, 2004.

[87] A. M. Bakken, C. D. Protack, E. Roztocil, S. M. Nicholl, and M. G. Davies, "Cell migration in response to the aminoterminal fragment of urokinase requires epidermal growth factor receptor activation through an ADAM-mediated mechanism," Journal of Vascular Surgery, vol. 49, no. 5, pp. 1296-1303, 2009.

[88] H. W. Smith and C. J. Marshall, "Regulation of cell signalling by uPAR," Nature Reviews Molecular Cell Biology, vol. 11, no. 1, pp. 23-36, 2010.

[89] T. Tarui, N. Akakura, M. Majumdar et al., "Direct interaction of the kringle domain of urokinase-type plasminogen activator (uPA) and integrin alpha v beta 3 induces signal transduction and enhances plasminogen activation," Thrombosis and Haemostasis, vol. 95, no. 3, pp. 524-534, 2006.

[90] R. M. Senior, W. F. Skogen, G. L. Griffin, and G. D. Wilner, "Effects of fibrinogen derivatives upon the inflammatory response. Studies with human fibrinopeptide B," The Journal of Clinical Investigation, vol. 77, no. 3, pp. 1014-1019, 1986.

[91] D. L. Richardson, D. S. Pepper, and A. B. Kay, "Chemotaxis for human monocytes by fibrinogen derived peptides," British Journal of Haematology, vol. 32, no. 4, pp. 507-513, 1976.

[92] T. J. Gross, K. J. Leavell, and M. W. Peterson, "CD11b/CD18 mediates the neutrophil chemotactic activity of fibrin degradation product D domain," Thrombosis and Haemostasis, vol. 77, no. 5, pp. 894-900, 1997.

[93] M. Naito, C. M. Stirk, E. B. Smith, and W. D. Thompson, "Smooth muscle cell outgrowth stimulated by fibrin degradation products: the potential role of fibrin fragment $\mathrm{E}$ in restenosis and atherogenesis," Thrombosis Research, vol. 98, no. 2, pp. 165-174, 2000.

[94] S. C. Robson, E. G. Shephard, and R. E. Kirsch, "Fibrin degradation product D-dimer induces the synthesis and release of biologically active IL- $1 \beta$, IL- 6 and plasminogen activator inhibitors from monocytes in vitro," British Journal of Haematology, vol. 86, no. 2, pp. 322-326, 1994.

[95] M. Hamaguchi, Y. Morishita, I. Takahashi, M. Ogura, J. Takamatsu, and H. Saito, "FDP D-dimer induces the secretion of interleukin-1, urokinase-type plasminogen activator, and plasminogen activator inhibitor-2 in a human promonocytic leukemia cell line," Blood, vol. 77, no. 1, pp. 94-100, 1991. 
[96] C. Jennewein, N. Tran, P. Paulus, P. Ellinghaus, J. A. Eble, and K. Zacharowski, "Novel aspects of fibrin(ogen) fragments during inflammation," Molecular Medicine, vol. 17, no. 5-6, pp. 568-573, 2011.

[97] R. V. Lalla, M. L. Tanzer, and D. L. Kreutzer, "Identification of a region of the fibrin molecule involved in upregulation of interleukin-8 expression from human oral squamous cell carcinoma cells," Archives of Oral Biology, vol. 48, no. 4, pp. 263271, 2003.

[98] M. Gröger, W. Pasteiner, G. Ignatyev et al., "Peptide B $\beta_{15-42}$ preserves endothelial barrier function in shock," PLOS ONE, vol. 4, no. 4, Article ID e5391, 2009.

[99] J. P. Roesner, P. Petzelbauer, A. Koch et al., "B $\beta 15-42$ (FX06) reduces pulmonary, myocardial, liver, and small intestine damage in a pig model of hemorrhagic shock and reperfusion," Critical Care Medicine, vol. 37, no. 2, pp. 598-605, 2009.

[100] K. Doronin, J. W. Flatt, N. C. di Paolo et al., "Coagulation factor $\mathrm{X}$ activates innate immunity to human species $\mathrm{C}$ adenovirus," Science, vol. 338, no. 6108, pp. 795-798, 2012.

[101] J. F. A. Swisher, N. Burton, S. M. Bacot, S. N. Vogel, and G. M. Feldman, "Annexin A2 tetramer activates human and murine macrophages through TLR4," Blood, vol. 115, no. 3, pp. 549-558, 2010.

[102] K. L. Allen, F. V. Fonseca, V. Betapudi, B. Willard, J. Zhang, and K. R. McCrae, "A novel pathway for human endothelial cell activation by antiphospholipid/anti-beta2 glycoprotein I antibodies," Blood, vol. 119, no. 3, pp. 884-893, 2012.

[103] K.-L. He, G. Sui, H. Xiong et al., "Feedback regulation of endothelial cell surface plasmin generation by PKC-dependent phosphorylation of annexin A2," The Journal of Biological Chemistry, vol. 286, no. 17, pp. 15428-15439, 2011.

[104] D. K. Ingawale, S. K. Mandlik, and S. S. Patel, "An emphasis on molecular mechanisms of anti-inflammatory effects and glucocorticoid resistance," Journal of Complementary and Integrative Medicine, vol. 12, no. 1, pp. 1-13, 2015.

[105] C. R. Keenan, S. Salem, E. R. Fietz, R. C. Gualano, and A. G. Stewart, "Glucocorticoid-resistant asthma and novel antiinflammatory drugs," Drug Discovery Today, vol. 17, no. 17-18, pp. 1031-1038, 2012.

[106] T. Tran, D. J. Fernandes, M. Schuliga, T. Harris, L. Landells, and A. G. Stewart, "Stimulus-dependent glucocorticoid-resistance of GM-CSF production in human cultured airway smooth muscle," British Journal of Pharmacology, vol. 145, no. 1, pp. 123131, 2005.

[107] J. V. Bonacci, M. Schuliga, T. Harris, and A. G. Stewart, "Collagen impairs glucocorticoid actions in airway smooth muscle through integrin signalling," British Journal of Pharmacology, vol. 149, no. 4, pp. 365-373, 2006.

[108] Y. Xie, K. Gao, L. Häkkinen, and H. S. Larjava, "Mice lacking $\beta 6$ integrin in skin show accelerated wound repair in dexamethasone impaired wound healing model," Wound Repair and Regeneration, vol. 17, no. 3, pp. 326-339, 2009.

[109] J. A. P. Spijkers-Hagelstein, S. M. Pinhanços, P. Schneider, R. Pieters, and R. W. Stam, "Src kinase-induced phosphorylation of annexin A2 mediates glucocorticoid resistance in MLLrearranged infant acute lymphoblastic leukemia," Leukemia, vol. 27, no. 5, pp. 1063-1071, 2013.

[110] J. Graff and S. Harder, "Anticoagulant therapy with the oral direct factor Xa inhibitors rivaroxaban, apixaban and edoxaban and the thrombin inhibitor dabigatran etexilate in patients with hepatic impairment," Clinical Pharmacokinetics, vol. 52, no. 4, pp. 243-254, 2013.
[111] S. L. French, J. F. Arthur, H. A. Tran, and J. R. Hamilton, "Approval of the first protease-activated receptor antagonist: rationale, development, significance, and considerations of a novel anti-platelet agent," Blood Reviews, 2014.

[112] D. Capodanno, D. L. Bhatt, S. Goto et al., "Safety and efficacy of protease-activated receptor-1 antagonists in patients with coronary artery disease: a meta-analysis of randomized clinical trials," Journal of Thrombosis and Haemostasis, vol. 10, no. 10, pp. 2006-2015, 2012.

[113] M. Zhu, V. M. Gokhale, L. Szabo et al., "Identification of a novel inhibitor of urokinase-type plasminogen activator," Molecular Cancer Therapeutics, vol. 6, no. 4, pp. 1348-1356, 2007.

[114] I. Henneke, S. Greschus, R. Savai et al., "Inhibition of urokinase activity reduces primary tumor growth and metastasis formation in a murine lung carcinoma model," The American Journal of Respiratory and Critical Care Medicine, vol. 181, no. 6, pp. 611619, 2010.

[115] M. Schmitt, N. Harbeck, N. Brünner et al., "Cancer therapy trials employing level-of-evidence-1 disease forecast cancer biomarkers uPA and its inhibitor PAI-1," Expert Review of Molecular Diagnostics, vol. 11, no. 6, pp. 617-634, 2011.

[116] I. K. Lund, M. G. Rasch, S. Ingvarsen et al., "Inhibitory monoclonal antibodies against mouse proteases raised in GeneDeficient mice block proteolytic functions in vivo," Frontiers in Pharmacology, vol. 3, article 122, 2012.

[117] K. A. Botkjaer, S. Fogh, E. C. Bekes et al., "Targeting the autolysis loop of urokinase-type plasminogen activator with conformation-specific monoclonal antibodies," Biochemical Journal, vol. 438, no. 1, pp. 39-51, 2011.

[118] X.-Q. Wang, K. Bdeir, S. Yarovoi, D. B. Cines, W. Fang, and E. Abraham, "Involvement of the urokinase kringle domain in lipopolysaccharide-induced acute lung injury," The Journal of Immunology, vol. 177, no. 8, pp. 5550-5557, 2006.

[119] J. Inokuchi, N. Narula, D. S. Yee et al., "Annexin A2 positively contributes to the malignant phenotype and secretion of IL-6 in DU145 prostate cancer cells," International Journal of Cancer, vol. 124, no. 1, pp. 68-74, 2009.

[120] M. R. Sharma, V. Rothman, G. P. Tuszynski, and M. C. Sharma, "Antibody-directed targeting of angiostatin's receptor annexin II inhibits Lewis Lung Carcinoma tumor growth via blocking of plasminogen activation: possible biochemical mechanism of angiostatin's action," Experimental and Molecular Pathology, vol. 81, no. 2, pp. 136-145, 2006.

[121] M. Sharma, M. R. Blackman, and M. C. Sharma, "Antibodydirected neutralization of annexin II (ANX II) inhibits neoangiogenesis and human breast tumor growth in a xenograft model," Experimental and Molecular Pathology, vol. 92, no. 1, pp. 175-184, 2012.

[122] L. Zheng and E. M. Jaffee, "Annexin A2 is a new antigenic target for pancreatic cancer immunotherapy," OncoImmunology, vol. 1, no. 1, pp. 112-114, 2012. 


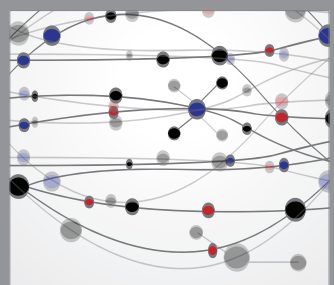

The Scientific World Journal
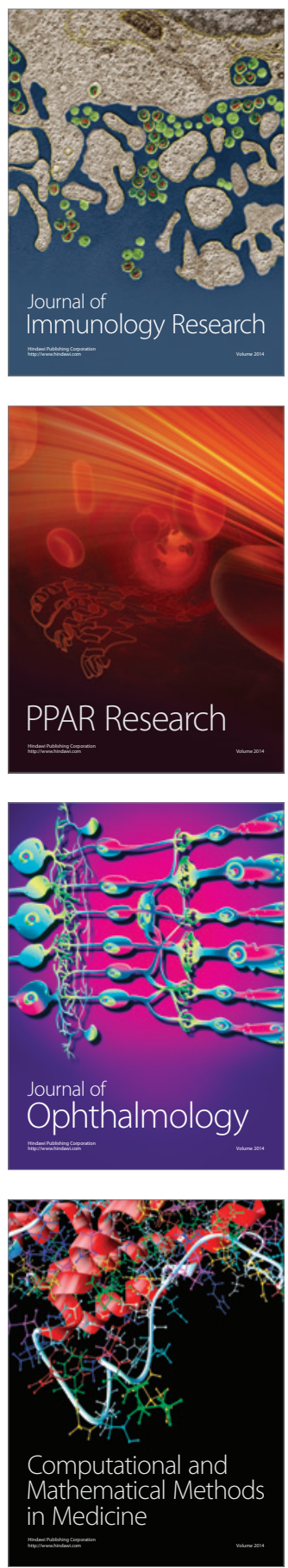

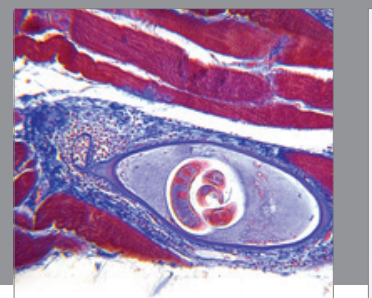

Gastroenterology

Research and Practice
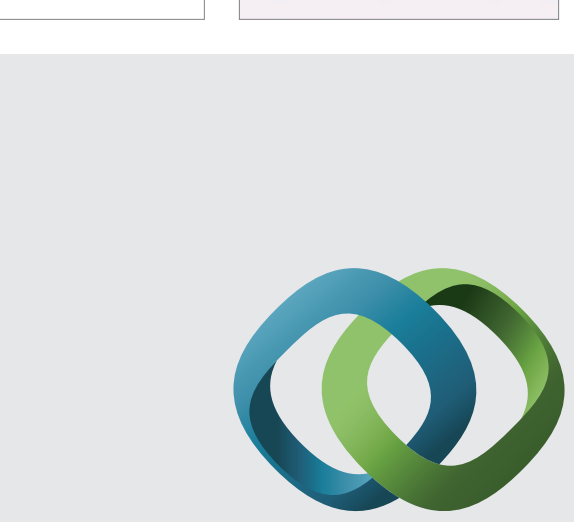

\section{Hindawi}

Submit your manuscripts at

http://www.hindawi.com
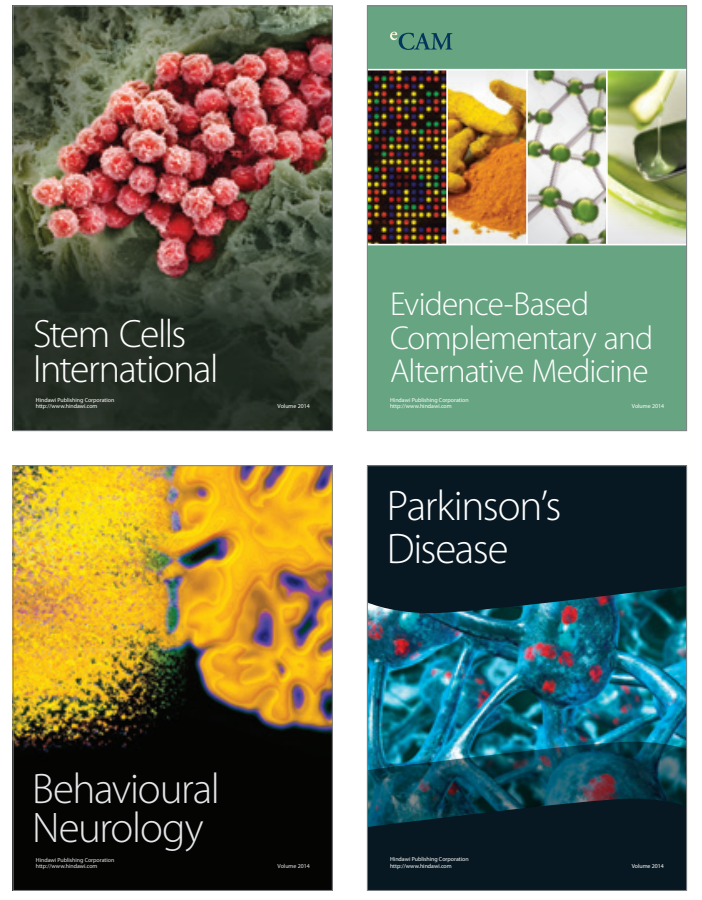
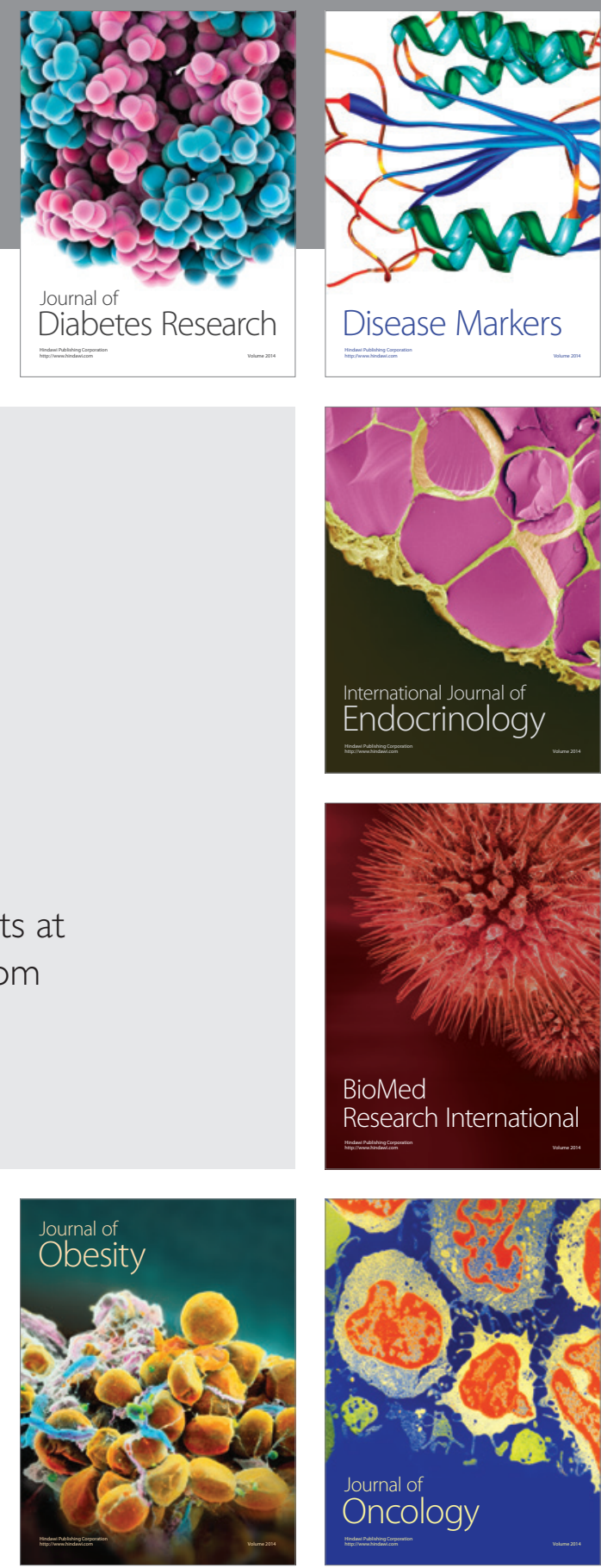

Disease Markers
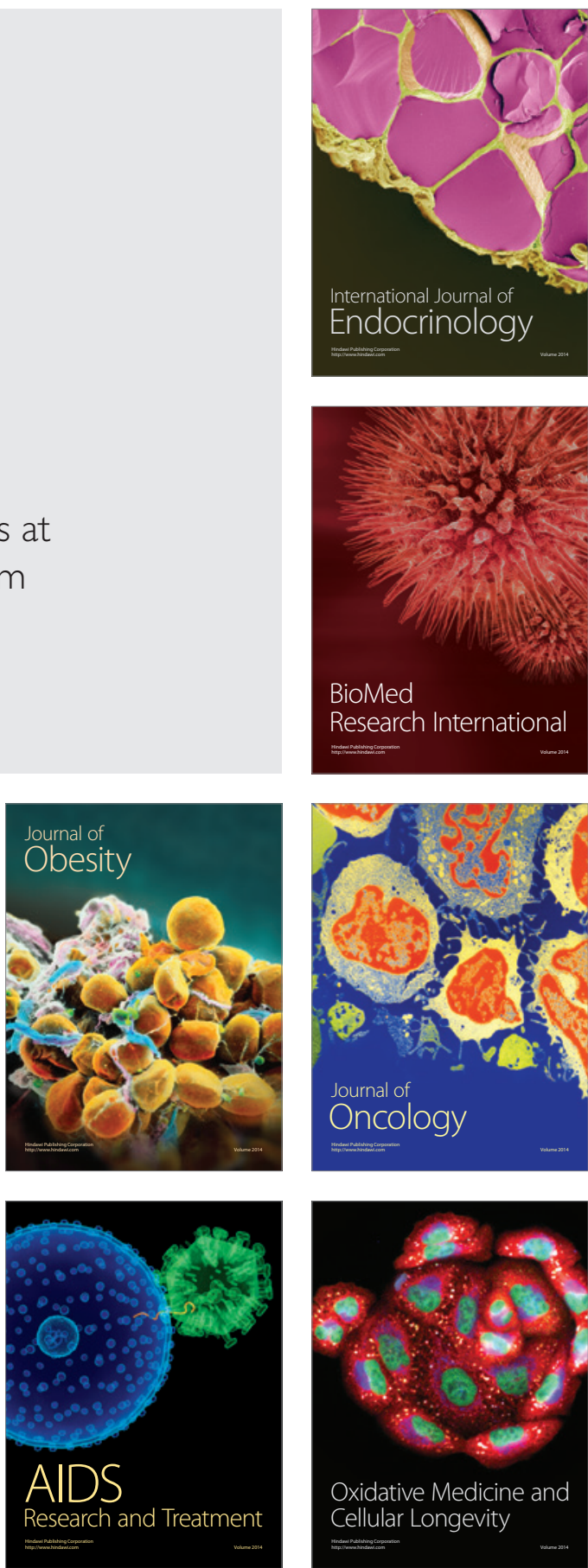